\title{
Influence of fibrinogen and C-RP on progression of peripheral arterial disease in type 2 diabetes: a preliminary report
}

\author{
Marijan Bosevski ${ }^{1}$, Golubinka Bosevska ${ }^{2}$ and Lily Stojanovska, $3,4^{*}$
}

\begin{abstract}
Background: Limited studies have suggested that inflammatory biomarkers play a role in the initiation and progression of atherosclerosis in diabetic patients. This study assesses the effect of inflammatory biomarkers: fibrinogen and C-reactive protein (C-RP) on the progression of peripheral arterial disease (PAD) in type 2 diabetic (T2D) patients.
\end{abstract}

Methods: Sixty two patients with T2D and PAD (mean age 60.28 \pm 27 years and diabetes duration of $8.58 \pm 6.17$ years) were enrolled in a cohort prospective study of 36 months. Ankle-brachial index (ABI) was measured in all patients at baseline and after 36 months. Multiple linear regression analysis was used to determine the predictivity of variables for fibrinogen, C-RP, plasma lipid fractions, fasting plasma glucose, Body Mass Index (BMI), duration of diabetes status and the age on changes in $\mathrm{ABI}$ value.

Results: Linear regression analysis defined $F$ as a predictor for endpoint value of $A B I(\beta=0.469, p=0.007)$. Value of C-RP determinates change of minimal value of $A B I(\beta=0.449, p=0.037)$ and change of mean $A B I$ per year $(\beta=0.442$, $\mathrm{p}=0.025)$.

Conclusion: Our data indicate that plasma determination of fibrinogen and C-RP might have a clinical implication in defining the process of progression of PAD in T2D population.

Keywords: ABI, Fibrinogen, C-RP, Type 2 diabetes, Peripheral arterial disease, Progression of atherosclerosis

\section{Background}

Previous studies have found accelerated atherosclerosis and increased risk of vascular disease in diabetic patients $[1,2]$. Risk factors such as hyperglycaemia and glucose intolerance, hyperlipidaemia, obesity and hypertension have been established as risk factors for diabetic vascular disease $[3,4]$.

However, very little is known about the potentially unique features of this inflammatory process in diabetic vascular disease. Some studies have suggested that the inflammatory biomarkers, C-RP and fibrinogen, play a role in initiation, aggravation of the classical pathways and progression of atherosclerosis in diabetic patients [5-7]. These biomarkers are more closely related with

\footnotetext{
* Correspondence: lily.stojanovska@vu.edu.au

${ }^{3}$ College of Health and Biomedicine, Victoria University, Melbourne, Australia ${ }^{4}$ School of Biomedical and Health Sciences, Victoria University, PO Box 14428, Melbourne, Vic 8001, Australia

Full list of author information is available at the end of the article
}

the metabolic syndrome and insulin resistance compared with cytokines, and they influence the onset of potential cardiovascular events [8].

Hyperfibrinogenemia, a condition of elevated level of fibrinogen in the blood, is found more frequently in diabetic patients with manifested peripheral arterial disease (PAD) and more severe coronary artery disease (CAD) [9]. High levels of C-RP have been found in advanced stages of atherosclerosis in diabetic patients, especially in those with high level of $\mathrm{HbA1C}$ and high concentration of advanced glycated proteins [10]. The purpose of this study was to determinate the influence of inflammatory biomarkers: fibrinogen and C-RP on progression of PAD in type 2 diabetic (T2D) patients as measured with changes in $\mathrm{ABI}$ values. 


\section{Methods}

Sixty seven patients with T2D and PAD were enrolled in a cohort prospective study between 2005 and 2008. Five patients were excluded from the study, while the remaining 62 patients that met the inclusion criteria were followed-up for 36 months. The study was conducted at the vascular laboratory at University Cardiology Clinic Skopje. The study was carried out according to the Helsinki declaration and was approved by the University Clinic Ethics Committee, Skopje.

Type 2 diabetes was defined based on the criteria of the International Diabetes Federation. Patients with PAD, stage Fontaine I, with an established value of $\mathrm{ABI}<0.9$ met the inclusion criteria for the study. Those with advanced PAD stage and with high, pathological ABI values, as well with acute inflammatory state (diabetic foot infection, cold, pneumonia) were excluded from the study. In all patients, we measured at baseline and after 36 months, at the completion of the study the ABI value, using a continuous wave Doppler (Hunleigh Healtcare, Cardiff, UK) to determine the lowest ABI values (ratio of ankle to brachial pressure). ABI was measured by vascular physicians with the same person being involved throughout the study. Inter-observer variability was up to $6 \%$, measured previously. Mean values were calculated from the average of two measurements. Following the endpoint measurement of the ABI, a change in ABI was also calculated.

Laboratory tests were conducted at the University Institute for Clinical Biochemistry. Fibrinogen and C-RP were determined using the BNII nephelometer ( $N$ HighSensitivity C-RP and N Antiserum to Human Fibrinogen;
Dade Behring). Serum levels of the following laboratory tests were measured at baseline and at 36 weeks in all patients: total cholesterol (enzymatic methods-in the presence of cholesterol oxidize), triglycerides (in the presence of glycerokinase), and the HDL fraction by direct method.

Automatic analyzer Coba Integra 400/700 (ROCHE Diagnostics) was used. The LDL fraction was evaluated using the Friedewald formula. Non-HDL cholesterol was determinate as a value of total cholesterol minus HDL cholesterol. Fasting plasma glucose concentration was evaluated using the enzymatic-photometric method, in the presence of glucoso-dehydrogenase. All analyses were done according recommendation of International Federation of Clinical Chemistry and Laboratory Medicine.

Multiple linear regression analysis was used to define continuous variables with predictive value for the ABI, when adjusted for systolic blood pressure, BMI index, diabetes duration, age, blood glucose, plasma lipid levels (total, LDL-, HDL- cholesterol), C-RP and fibrinogen. The data is expressed as mean $\pm \mathrm{SD}$.

\section{Results}

Sixty-two participants were included for analysis, comprising 39 males and 23 females. The baseline characteristics for the study population were as follows: mean age of $60.28 \pm 27$ years; mean diabetes duration of $8.58 \pm 6.17$ years, and overweight status by BMI (mean BMI $28.7+4 \mathrm{~kg} / \mathrm{m}^{2}$.

At baseline the mean fasting plasma glucose of the group was $8.5 \pm 2.4 \mathrm{mmol} / \mathrm{L}$, mean plasma fibrinogen level was $4.12 \pm 0.85 \mathrm{~g} / \mathrm{L}$ and had a mean of C-RP of $5.69 \pm 1.92 \mathrm{mmol} / \mathrm{L}$. Measurements of the lipid profile at

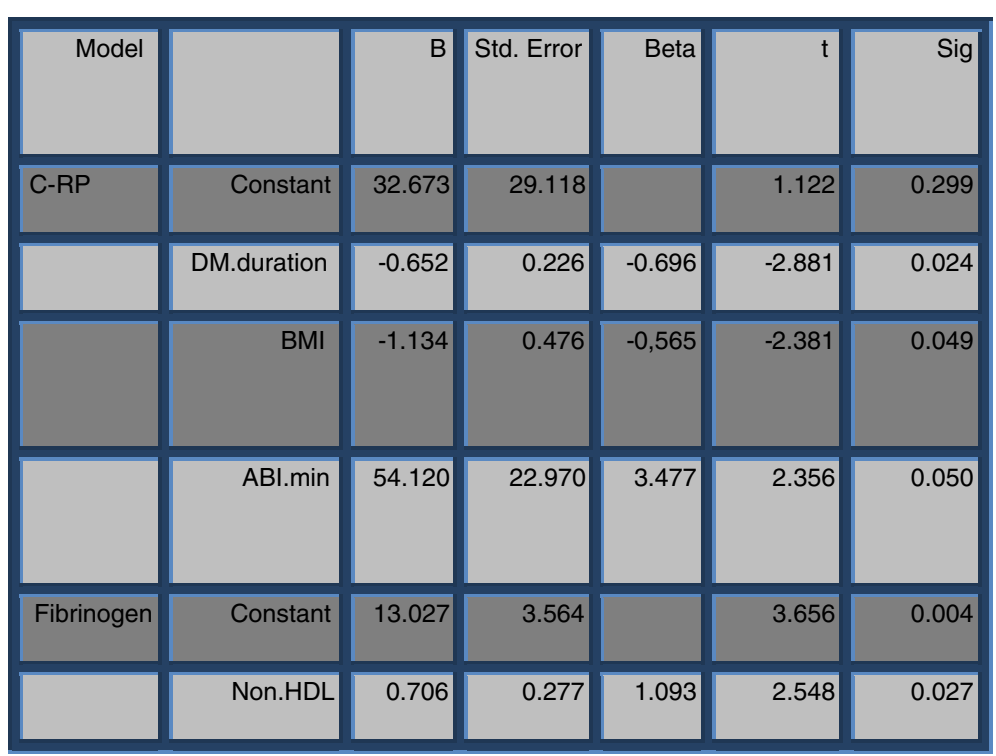

Figure 1 Multiple linear regression analysis for factors for C-RP and fibrinogen. 
baseline show total cholesterol of $5.4 \pm 1.4 \mathrm{mmol} / \mathrm{L}$, LDL-cholesterol of $3.3 \pm 0.9 \mathrm{mmol} / \mathrm{L}$, and HDL-cholesterol of $1.0 \pm 0.4 \mathrm{mmol} / \mathrm{L}$.

Of all the patients $98.4 \%$ received acetyl salicylic acid, while $85.4 \%$ received statins. Furthermore, $59.6 \%$ of the patients were treated with oral anti-diabetics and $41.4 \%$ of them with insulin.

The measurements of the $\mathrm{ABI}$ indexes at baseline were: $\mathrm{ABIx}=0.83 \pm 0.04$ (mean) and ABImin $=0.75+$ 0.07 (lowest), while following the 36 months we found $\mathrm{ABIx}=0.45 \pm 0.05$ and ABImin $=0.48 \pm 0.06$. Significant changes of minimal value of $\mathrm{ABI}(\mathrm{dABImin}=0.38 \pm 3.1)$ and mean $\mathrm{ABI}(\mathrm{dABIx}=0.27 \pm 0.21)$ were found. No gender differences were found according ABI indexes.

Multivariate analysis showed that $F$ value has been determined with non HDL - cholesterol $(\beta=1.093, \mathrm{p}=$ 0.027 ). Linear regression analysis defined fibrinogen as a predictor for minimal value of $\mathrm{ABI}$, found at the completion of the study $(\beta=0.469, p=0.007)$.
The value of C-RP was independently determined with diabetes duration, $\mathrm{BMI}$ and minimal value of $\mathrm{ABI}$, according to the results of multiple linear regression analysis. Fibrinogen was determinated with the value of non HDL - cholesterol (Figure 1).

Linear regression analysis defined fibrinogen as predictor for minimal value of $\mathrm{ABI}$, found at the end completion of the study $(\beta=0.469, p=0.007)$. The value of $\mathrm{C}$-RP determinates the change of minimal value of $\mathrm{ABI}$ (dABImin) and the change of mean $A B I$ per year $(\mathrm{dABIx} / \mathrm{y})$ (Figure 2).

\section{Discussion}

Patients with T2D often present with hypercoagulability, which may be related to changes in inflammatory biomarkers [11]. Patients with vascular disease and T2D presented higher values of inflammation markers when compared with patients without vascular disease [12]. In

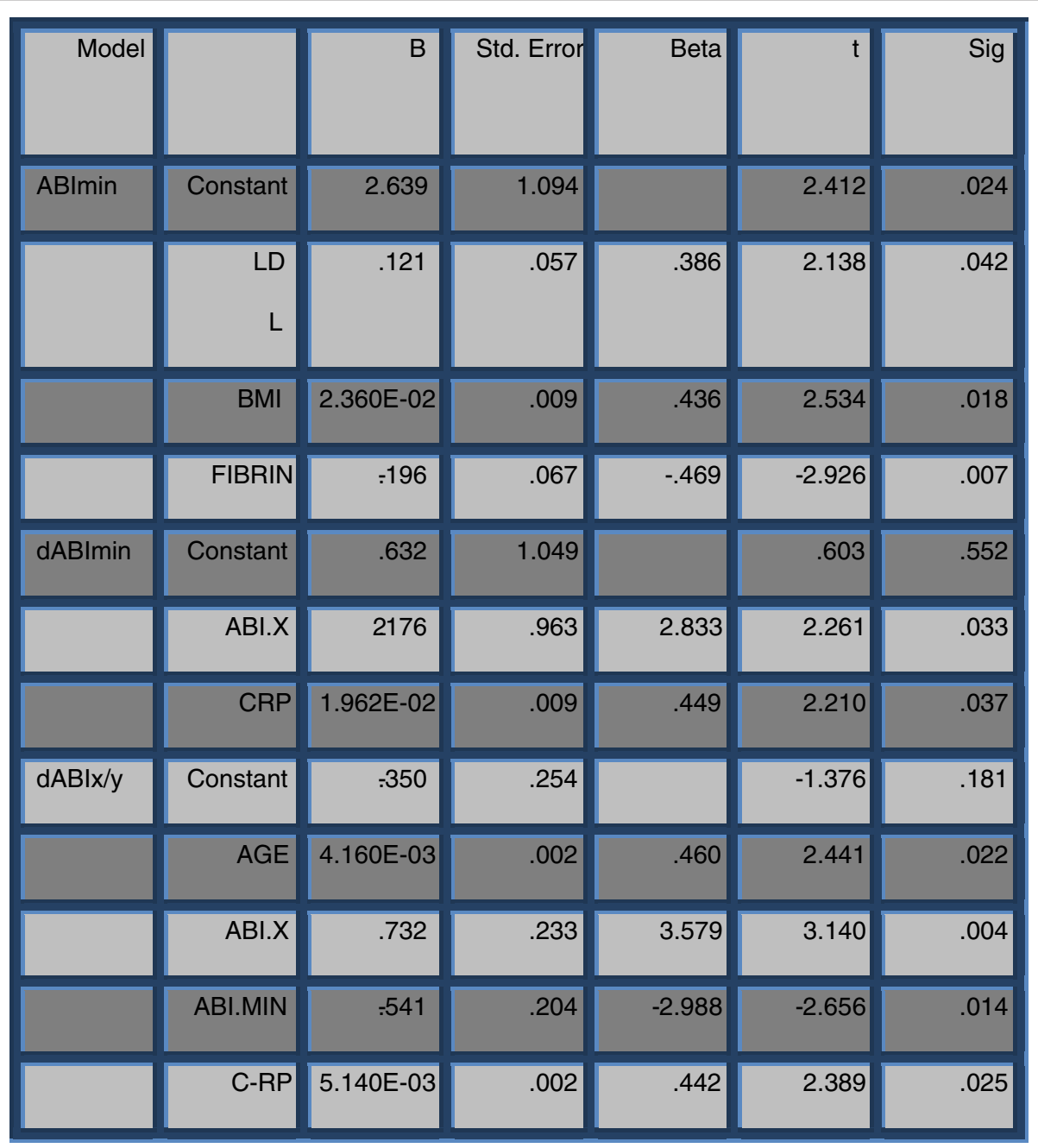

Figure $2 \mathrm{C}-\mathrm{RP}$ and Fibrinogen as factors for progression of $\mathrm{ABI}$ (multiple linear regression analysis). 
our study, both biomarkers, C-RP and fibrinogen, were significantly elevated.

\section{Impact of fibrinogen}

Fibrinogen and non-HDL cholesterol have synergistic effects, as factors accelerating the progression of carotid atherosclerosis [13]. Fibrinogen increases atherogenic dislipidaemia in diabetic patients. Fibrates act synergistically in the regulation of dispilidaemia, reduction in fibrinogen, triglycerides, LDL and non HDL- cholesterol $[14,15]$. Increased fibrinogen, as an inflammatory, haemostatic component, is present in diabetic patients, who are on oral hypoglycaemic as well as on insulin therapy [16].

Studies have shown that fibrinogen is associated with diabetes regulation, age, hypertension and components of the metabolic syndrome $[17,18]$.

Increased fibrinogen levels are often present in diabetic patients with PAD, and there is a correlation with fibrinogen values and angiographic extent of the disease $[19,20]$. Fibrinogen compared with C-RP might be closely associated with diabetic vascular disease [21]. The minimal value of ABI, found at the completion of our study correlates with the levels of fibrinogen measured at baseline. Fibrinogen values over $3.5 \mathrm{~g} / \mathrm{L}$ have been shown previously to be an independent marker for progressive cardiac events in diabetic patients [22]. Our results show that increased fibrinogen level of $>4 \mathrm{~g} / \mathrm{L}$ is a risk factor for progression of $\mathrm{PAD}$, as assessed by a decrease of $\mathrm{ABI}$ value.

Some studies have implied that the process of inflamation is the bridge between metabolic syndrome, insulin resistance and atherosclerosis [23]. As the latter causes are highly prevalent in diabetic patients, it is expected to observe a presence of significant inflamation in diabetic patients. Inflamation influences development of prediabetic phase in type 2 diabetes mellitus [24].

\section{C-RP in diabetic vascular disease}

According to our results the C-RP value is independently connected with diabetes duration, $\mathrm{BMI}$ and $\mathrm{ABI}$ index. Obesity is a major risk factor, correlated with C$\mathrm{RP}$ in populations with metabolic syndrome and/or T2D $(A D O P T)[25,26]$. Follow up studies in diabetic patients with coronary and carotid atherosclerosis, have shown that advanced atherosclerosis in T2D is connected with increased C-RP values and increased concentrations of advanced glycosylation products [27]. This high cardiovascular risk may be due to a combination of non-classical risk factors associated with insulin resistance, e.g. inflammation, hyperinsulinemia, oxidative stress, and hypercoagulability, together with the separate components of metabolic syndrome $[28,29]$.

Serum C-RP level was independently associated with PAD in T2D in a cross-sectional study by $\mathrm{Yu}$ and associates [30]. Our longitudinal study has shown that
$\mathrm{C}-\mathrm{RP}$ is an independent factor for dynamic change of minimal and mean values of $\mathrm{ABI}$.

\section{Therapeutic possibilities}

Potential applications of these observations have implications in clinical management of T2D patients with PAD. Previous studies imply that measuring inflammatory biomarkers may improve the definition of cerebrovascular risk profile in patients with type 2 diabetes [31]. Improvement of inflammatory state in diabetic population is associated with improvement of glyco-metabolic control. The use of insulin, metformin, sulfonylurea, thiazolindiones, and especially high doses of statins, according to the above studies, lead to reduction in C-RP and other inflammatory biomarker values in patients with T2D [32-36]. The use of statins, fibrates and glitazones although favorable, are not sufficient to cause the progression of diabetic vascular disease $[37,38]$.

\section{Limitations}

$A B I$ is defined as reliable marker for definition PAD, despite numerous factors that influence its value [39]. We measured progression of peripheral atherosclerosis using this index.

Our results are of a preliminary nature and as such this study has limitations due to its small sample size. Larger prospective studies in the future are therefore necessary.

\section{Conclusion}

Our results indicate that fibrinogen and C-RP independently influence the progression of peripheral atherosclerosis in T2D patients. Plasma determination of these inflammatory biomarkers might have an implication in predicting the clinical course of peripheral arterial disease in T2D population.

\section{Abbreviations \\ T2D: Type 2 Diabetes; PAD: Peripheral arterial disease; ABI: Ankle-brachial index; C-RP: C-Reactive protein.}

\section{Competing interests}

The authors declare that they have no competing interests.

\section{Authors' contribution}

MB: design and results of study. GB: contributed to biomarker analysis and related discussion. LS: revised the manuscript critically for important intellectual content. All authors read and approved the final manuscript.

\section{Acknowledgements}

The authors wish to thank the participants in the study, and acknowledge the contribution of Mrs Kristina Nelson, Victoria University, for her editorial assistance of this paper and Mrs Saska Domazetovska, University Clinic for Clinical Biochemistry for her assistance in the part of laboratory methods.

\section{Author details}

${ }^{1}$ Medical Faculty, University Cardiology Clinic, Skopje, Macedonia. ${ }^{2}$ Institute for Public Health of R. Macedonia, Skopje, Macedonia. ${ }^{3}$ College of Health and Biomedicine, Victoria University, Melbourne, Australia. ${ }^{4}$ School of Biomedical and Health Sciences, Victoria University, PO Box 14428, Melbourne, Vic 8001, Australia. 
Received: 23 January 2013 Accepted: 27 January 2013

Published: 1 February 2013

\section{References}

1. Raggi P, Cooil B, Ratti C, Callister TQ, Budoff M: Progression of coronary artery calcium and occurrence of myocardial infarction in patients with and without diabetes mellitus. Hypertension 2005, 46(1):238-243.

2. Alvarsson A, Sandgren B, Wendel C, Alvarsson M, Brismar K: A retrospective analysis of amputation rates in diabetic patients: can lower extremity amputations be further prevented? Cardiovasc Diabetol 2012, 11:18.

3. Wagenknecht LE, D'Agostino R Jr, Savage PJ, O'Leary DH, Saad MF, Haffner SM: Duration of diabetes and carotid wall thickness. The Insulin Resistance Atherosclerosis Study (IRAS). Stroke 1997, 28:999-1005.

4. Sander D, Schulze-Horn C, Bickel H, Gnahn H, Bartels E, Conrad B: Combined effects of hemoglobin A1C and C-reactive protein on the progression of subclinical carotid atherosclerosis: the INVADE study. Stroke 2006, 37(2):351-357.

5. Ross R: Atherosclerosis: an inflammatory disease. N Engl J Med 1999, 314:115-126.

6. Hayden M, Tyagi S: Intimal redox stress: Accelerated atherosclerosis in metabolic syndrome and type 2 diabetes mellitus, Atheroscleropathy. Cardiovasc Diabetol 2002, 1(3):1-27.

7. Poulsen MK, Nybo M, Dahl J, Hosbond S, Poulsen TS, Johansen A, HøilundCarlsen PF, Beck-Nielsen H, Rasmussen LM, Henriksen JE: Plasma osteoprotegerin is related to carotid and peripheral arterial disease, but not to myocardial ischemia in type 2 diabetes mellitus. Cardiovasc Diabetol 2011, 10:76.

8. Goldberg RB: Cytokine and cytokine-like inflammation markers, endothelial dysfunction, and imbalanced coagulation in development of diabetes and its complications. J Clin Endocrinol Metab 2009, 94(3):3171-3182.

9. O'Neal DN, Dragicevic G, Rowley KG, Ansari MZ, Balazs N, Jenkins A, et al: A cross-sectional study of the effects of type 2 diabetes and other cardiovascular risk factors on structure and function of nonstenotic arteries of the lower limb. Diabetes Care 2003, 26(1):199-205.

10. Tan KC, Chow WS, Tam S, Bucala R, Betteridge J: Association between acute-phase reactants and advanced glycation end products in type 2 diabetes. Diabetes Care 2004, 27(1):223-228.

11. Beijers HJ, Ferreira I, Spronk HM, Bravenboer B, Dekker JM, Nijpels G, Ten Cate $\mathrm{H}$, Stehouwer CD: Impaired glucose metabolism and type 2 diabetes are associated with hypercoagulability: potential role of central adiposity and low-grade inflammation -The Hoorn Study. Thromb Res 2012, 129(5):557-562.

12. Akalin A, Alatas O, Colak O: Relation of plasma homocysteine levels to atherosclerotic vascular disease and inflammation markers in type 2 diabetic patients. Eur J Endocrinol 2008, 158:47-52.

13. Rizzo M, Corrado E, Coppola G, Muratori I, Novo G, Novo S: Prediction of cardio- and cerebro-vascular events in patients with subclinical carotid atherosclerosis and low HDL-cholesterol. Atherosclerosis 2008, 56(1):32-40.

14. Mertens I, Lemieux I, Verrijken A, Després JP, Van Gaal LF: PAl-1 activity, but not fibrinogen or von Willebrand factor, is inversely related to LDL particle size in type 2 diabetes. Diabetes Metab Res Rev 2008, 24(2):141-147.

15. Bianchi C, Penno G, Malloggi L, Barontini R, Corfini M, Giovannitti MG, et al: Non-traditional markers of atherosclerosis potentiate the risk of coronary heart disease in patients with type 2 diabetes and metabolic syndrome. Nutr Metab Cardiovasc Dis 2008, 18(1):31-38.

16. Wu TJ, Ou HY, Chou CW, Hsiao SH, Lin CY, Kao PC: Decrease in inflammatory cardiovascular risk markers in hyperlipidemic diabetic patients treated with fenofibrate. Ann Clin Lab Sci 2007, 37(2):158-166.

17. Knöbl P, Schernthaner G, Schnack C, Pietschmann P, Proidl S, Prager R, et al: Haemostatic abnormalities persist despite glycaemic improvement by insulin therapy in lean type 2 diabetic patients. Thromb Haemost 1994, 71(6):692-697.

18. Bruno G, Cavallo-Perin P, Bargero G, Borra M, D'Errico N, Macchia G, et al: Hyperfibrinogenemia and metabolic syndrome in type 2 diabetes: a population-based study. Diabetes Metab Res Rev 2001, 17(2):124-130

19. Lam TH, Liu LJ, Janus ED, Lam KS, Hedley AJ: Hong Kong Cardiovascular Risk Factor Prevalence Study Steering Committee. Fibrinogen, other cardiovascular risk factors and diabetes mellitus in Hong Kong: a community with high prevalence of Type 2 diabetes mellitus and impaired glucose tolerance. Diabet Med 2000, 17(11):798-806.

20. Bosevski M, Borozanov V, Peovska I, Georgievska-Ismail L: Endothelial dysfunction correlates with plasma fibrinogen and HDL cholesterol in type 2 diabetic patients with coronary artery disease. Bratis/ Lek Listy 2007, 108(7):297-300.

21. Takebayashi K, Suetsugu M, Matsutomo R, Wakabayashi S, Aso Y, Inukai T: Correlation of high-sensitivity C-reactive protein and plasma fibrinogen with individual complications in patients with type 2 diabetes. South Med J 2006, 99:23-27.

22. Hutajulu SH, Kurnianda J, Purwanto I, Asdie RH, Wiyono P, Asdie AH: Fibrinogen and plasminogen activator inhibitor- 1 level in peripheral arterial disease of type 2 diabetes patients. Acta Med Indones 2006, 38(3):126-129.

23. Schmechel $H$, Beiküfner $P$, Panzram G: Longitudinal studies on the prognostic significance of plasma fibrinogen in diabetes mellitus. Z Gesamte Inn Med 1984, 39(18):453-457.

24. Ziegler D: Type 2 diabetes as an inflammatory cardiovascular disorder. Curr Mol Med 2005, 5(3):309-322.

25. Nesto R: C-reactive protein, its role in inflammation, Type 2 diabetes and cardiovascular disease, and the effects of insulin-sensitizing treatment with thiazolidines. Diabet Med 2004, 21(8):810-817.

26. Kahn SE, Zinman B, Haffner SM, O'Neill MC, Kravitz BG, Yu D, et al: ADOPT Study Group. Obesity is a major determinant of the association of Creactive protein levels and the metabolic syndrome in type 2 diabetes. Diabetes 2006, 55(8):2357-2364

27. Zaciragić A, Huskić J, Hadzović-Dzuvo A, Valjevac A, Avdagić N, Mulabegović $\mathrm{N}$ : Serum C-reactive protein concentration and measures of adiposity in patients with type 2 diabetes mellitus. Bosn J Basic Med Sci 2007, 7(4):322-327.

28. Moussavi N, Renier G, Roussin A, Mamputu JC, Buithieu J, Serri O: Lack of concordance between plasma markers of cardiovascular risk and intimamedia thickness in patients with type 2 diabetes. Diabetes Obes Metab 2004, 6(1):69-77.

29. Verhagen SN, Wassink AM, van der Graaf Y, Gorter PM, Visseren FL, SMART Study Group: Insulin resistance increases the occurrence of new cardiovascular events in patients with manifest arterial disease without known diabetes. The SMART study. Cardiovasc Diabetol 2011, 10:100.

30. Yu HI, Sheu WH, Song YM, Liu HC, Lee WJ, Chen YT: C-reactive protein and risk factors for peripheral vascular disease in subjects with Type 2 diabetes mellitus. Diabet Med 2004, 21(4):336-341.

31. Kadoglou NP, Avgerinos ED, Liapis CD: An update on markers of carotid atherosclerosis in patients with Type 2 diabetes. Biomark Med 2010, 4:601-609.

32. Viberti G, Kahn SE, Greene DA, Herman WH, Zinman B, Holman RR, et al: A diabetes outcome progression trial (ADOPT): an international multicenter study of the comparative efficacy of rosiglitazone, glyburide, and metformin in recently diagnosed type 2 diabetes. Diabetes Care 2002, 25(10):1737-1743.

33. Derosa G, Fogari E, Cicero AF, D'Angelo A, Ciccarelli L, Piccinni MN, et al: Blood pressure control and inflammatory markers in type 2 diabetic patients treated with pioglitazone or rosiglitazone and metformin. Hypertens Res 2007, 30(5):387-394.

34. Sobel BE, Hardison RM, Genuth S, Brooks MM, McBane RD 3rd, Schneider DJ, Pratley RE, Huber K, Wolk R, Krishnaswami A, Frye RL, for the BARI 2D Investigators: Profibrinolytic, Antithrombotic, and Antiinflammatory Effects of an Insulin-Sensitizing Strategy in Patients in the Bypass Angioplasty Revascularization Investigation 2 Diabetes (BARI 2D) Trial. Circulation 2011, 124(6):695-703.

35. Joya-Galeana J, Fernandez M, Cervera A, Reyna S, Ghosh S, Triplitt C, Musi N, DeFronzo RA, Cersosimo E: Effects of insulin and oral anti-diabetic agents on glucose metabolism, vascular dysfunction and skeletal muscle inflammation in type 2 diabetic subjects. Diabetes Metab Res Rev 2011, 27(4):373-382.

36. Forst $T$, Wilhelm B, Pfützner A, Fuchs W, Lehmann U, Schaper F, et al: Investigation of the vascular and pleiotropic effects of atorvastatin and pioglitazone in a population at high cardiovascular risk. Diabetes Vasc Dis Res 2008, 5:298-303.

37. Wägner AM, Sánchez-Quesada JL, Benítez S, Bancells C, Ordóñez-Llanos J, Pérez A: Effect of statin and fibrate treatment on inflammation in type 2 diabetes. A randomized, cross-over study. Diabetes Res Clin Pract 2011, 93(1):e25-e28. 
38. Krysiak R, Gdula-Dymek A, Okopien B: Effect of simvastatin and fenofibrate on cytokine release and systemic inflammation in type 2 diabetes mellitus with mixed dyslipidemia. Am J Cardiol 2011, 107(7):1010-1018.e1.

39. Xiao L, Huang DS, Tong JJ, Shen J: Efficacy of endoluminal interventional therapy in diabetic peripheral arterial occlusive disease: a retrospective trial. Cardiovasc Diabetol 2012, 11:17.

doi:10.1186/1475-2840-12-29

Cite this article as: Bosevski et al: Influence of fibrinogen and C-RP on progression of peripheral arterial disease in type 2 diabetes:

a preliminary report. Cardiovascular Diabetology 2013 12:29.

\section{Submit your next manuscript to BioMed Central and take full advantage of:}

- Convenient online submission

- Thorough peer review

- No space constraints or color figure charges

- Immediate publication on acceptance

- Inclusion in PubMed, CAS, Scopus and Google Scholar

- Research which is freely available for redistribution 